\title{
Influence of Lance Configuration Coal Combustion in Blast Furnace
}

\author{
Zhenfeng Zhou*, Guang Wang \\ State Key Laboratory of Advanced Metallurgy, University of Science and Technology Beijing, No.30, \\ Xueyuan Road, Haidian District, Beijing City, China.
}

Keywords: blast furnace,raceway,lance position, lance area

\begin{abstract}
In this paper, a numerical model simulating the lance-blowpipe-tuyere-raceway of a blast furnace has been developed. The coal flow and combustion along the coal plume are studied. The effect of the lance tip area and position on coal combustion is investigated.. The simulation results indicate that the coal burnout is increased with increase of the lance tip distance from the raceway. The coal burnout is also increased with increase of the lance tip area, and the influence is very obvious.
\end{abstract}

\section{Introduction}

The blast furnace $(\mathrm{BF})$ is the main process to produce hot metal due to its high productivity and heat utilization compared to other ironmaking technologies[1,2]. In the production of hot metal, much pulverized coal is injected into the blast furnace to replace partial of coke to reduce the cost and emission of $\mathrm{CO}_{2}$ [3].Therefore, how to improve coal ratio has been a problem of ironmaking for a long time.

Practically, coal burnout can't be improved not because of lack of oxygen in raceway region, but because of lack of local oxygen around the coal particles. By adjusting the lance configuration and positioning, coal particles can distribute more uniformly in the raceway, and coal burnout can be increased to a certain degree.

The reactions in the raceway are complex, and the environment is harsh. Therefore, it is very difficult to carry out a trial of pulverized coal injection (PCI) in the BF. However, computational fluid dynamic (CFD) provides a new method for the investigation of PCI in BF. Many investigations on the coal combustion in blast furnace (BF) using CFD have demonstrated its reliability and superiority[6-10]. Therefore, in this study, the coal combustion in theBF is investigated using CFD. The simulation results provide a useful insight into the pulverized coal injection in the BF.

\section{Mathematical Model}

The gas-particle flow and coal combustion in the tuyere and raceway region were calculated based on the framework of software package ANSYS-FLUENT. The mathematical formulation is described elsewhere[6-8,11,12].The pulverized coal particles are treated as discrete phase, modeled using the Lagrangian method. The governing equations for the particle and gas phase are described elsewhere[12,11,6-8].

\section{Geometry and Operating Conditions}

The main operational parameters of the TBF are summarized in Table 1.

The model simulates the lance-blowpipe-tuyere-raceway of BF. The detailed parameters are shown in Fig. 1. The TBF of $120 \mathrm{~m}^{3}$ was dissected in 2007. The results of the blast furnace dissection show that the depth of the raceway was about $700 \mathrm{~mm}$. The raceway is designed as a tube of $700 \mathrm{~mm}$ long with a divergence angle of $3^{\circ}$ referring to others[8]. 
Table 1Main Blast Parameters

\begin{tabular}{cccc}
\hline $\begin{array}{c}\text { Blast Volume } \\
\left(\mathrm{Nm}^{3} / \mathrm{t}\right)\end{array}$ & $\begin{array}{c}\text { Blast Temperature } \\
(\mathrm{K})\end{array}$ & $\begin{array}{c}\text { Volume } \\
\left(\mathrm{m}^{3}\right)\end{array}$ & $\begin{array}{c}\text { Coal Ratio } \\
(\mathrm{kg} / \mathrm{t})\end{array}$ \\
\hline 1129 & 1473 & 120 & 150 \\
\hline
\end{tabular}

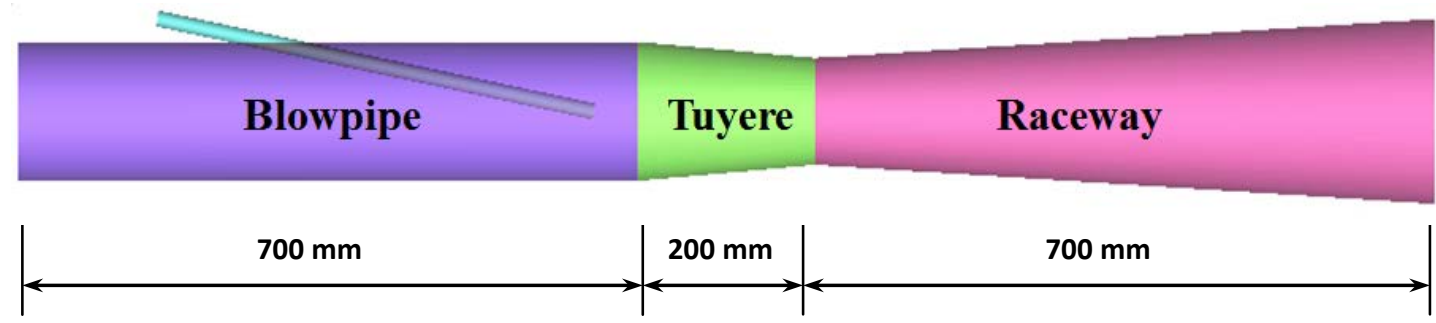

Fig. 1 Geometry of the model

\section{Results and Discussion}

Model Validation. CFD has been extensively used for the simulation of coal combustion, and the reliability of this approach has been fully proved[6-8,13,14,10,15]. Before investigating the coal combustion in OBF, the simulation on coal combustion in the TBF is carried out. The simulation results and phenomena are very similar to those of others[11,12]. These comparisons have fully illustrated the reliability of this model.

Effect of the lance tip position. In some cases, the combustion of pulverized coal in the raceway region is insufficient, partly because the local oxygen around the pulverized coal is lacking and partly because the residence time in the raceway is very short. The pulverized coal particles leave the raceway without burning completely. If the residence time of coal particles in the raceway is lengthened, coal burnout in the raceway may be improved. And by extending the distance of the lance tip from the tuyere, the residence time in the raceway will be lengthened. And the coal burnout may be improved. In this part, the effect of the distance of the lance tip from the tuyere on the coal combustion is studied.

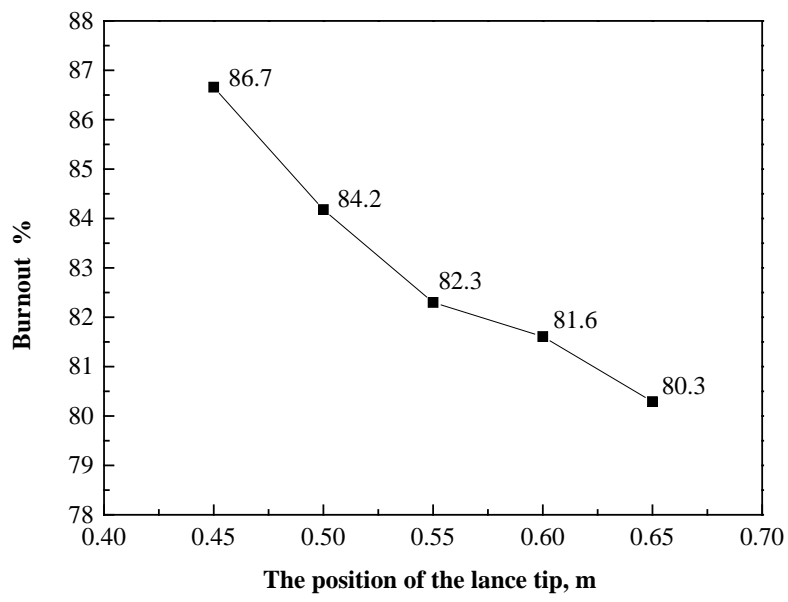

Fig. 2Effect of the lance tip position on coal burnout

Fig. 2 shows the effect of the lance tip position on the coal burnout. It is shown that the coal burnout is increased as increase of the distance of the lance tip from the raceway. When the distance increases from $0.05 \mathrm{~m}$ to $0.25 \mathrm{~m}$, the coal burnout is increased from $80.3 \%$ to $86.7 \%$. There is only slight increase in the coal burnout, from $80.3 \%$ to $82.3 \%$, when the distance increases from $0.05 \mathrm{~m}$ to $0.15 \mathrm{~m}$. There is obvious increase in the coal burnout, from $82.3 \%$ to $86.7 \%$, when the distance increases from $0.15 \mathrm{~m}$ to $0.25 \mathrm{~m}$. Practically, increasing the distance of the lance tip from the 
raceway extends the combustion distance. The coal particles can be sufficiently heated and burns vigorously.

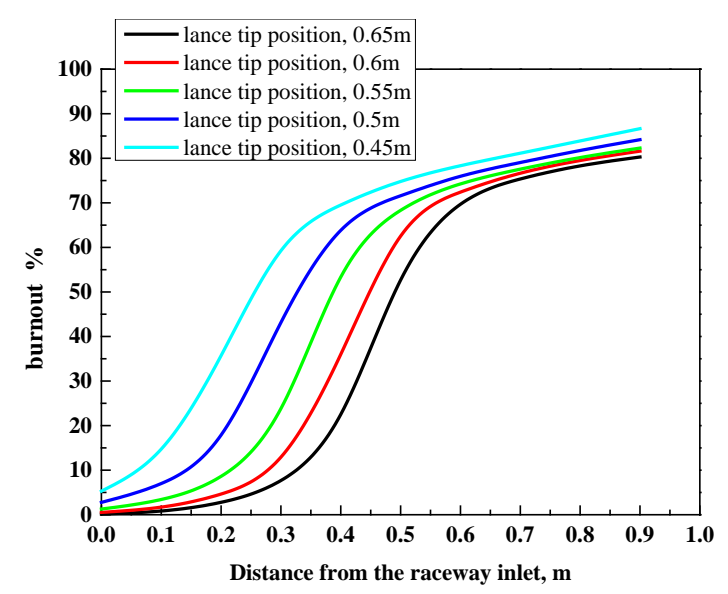

Fig. 3Effect of the lance tip position on coal burnout changes in the raceway

Fig. 2 only shows the effect of the lance tip position on final burnout, namely the burnout of the raceway outlet. In order to compare the effect of the lance tip position on coal combustion characteristics through the coal flow, the coal burnout at different locations of the raceway is calculated,as shown in Fig. 3. Fig. 3 shows that the coal burnout at each position is increased with increase of the distance of the lance tip from the raceway. In the direction of axis $+X$, the coal burnout increases gradually, and at a certain point the coal burnout increases rapidly. However, in position the increase rate slows down. When the distance of the lance tip from the raceway increases from $0.05 \mathrm{~m}$ to $0.25 \mathrm{~m}$, at the distance of $0.3 \mathrm{~m}$, the coal burnout increases from $7.7 \%$ to $59.3 \%$, and the burnout is increased by $51.6 \%$; At the distance of $0.4 \mathrm{~m}$, the coal burnout increases from $22.5 \%$ to $69.5 \%$, and the burnout is increased by $47 \%$. From the distance of $0.5 \mathrm{~m}$, the effect of the lance tip position on the coal burnout is more and more small. At the outlet of the raceway, the coal burnout is increased only by $6.4 \%$.

Effect of the lance tip area. In this part, effect of the lance tip area on coal combustion is investigated. The lance tip diameters are $15 \mathrm{~mm}, 20 \mathrm{~mm}$ and $25 \mathrm{~mm}$, respectively. The lance tip central position is $0.65 \mathrm{~m}$ of the center line in the direction of axis $+\mathrm{X}$.

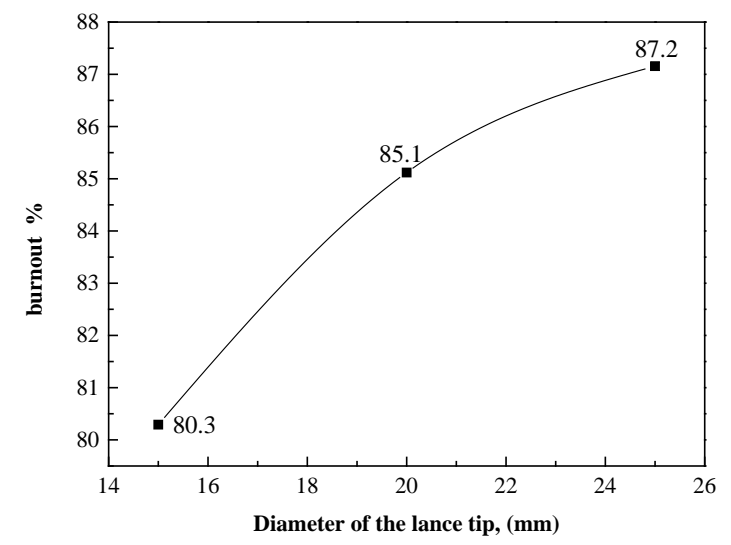

Fig. 4Effect of the lance tip area on coal burnout

Fig. 4shows effect of the lance tip area on coal burnout. It shows that the coal burnout increases with increase of the lance tip area. When the lance tip diameter increases from $15 \mathrm{~mm}$ to $25 \mathrm{~mm}$, the coal burnout increases from $80.3 \%$ to $87.2 \%$. The coal burnout increases by $6.9 \%$. With increase of the lance tip area, the average velocity of coal particles flowing into the blowpipe reduces. On the other hand, with increase of the lance tip area, the distribution of the coal particles is more uniform, which is more favorable for combustion of the coal. 


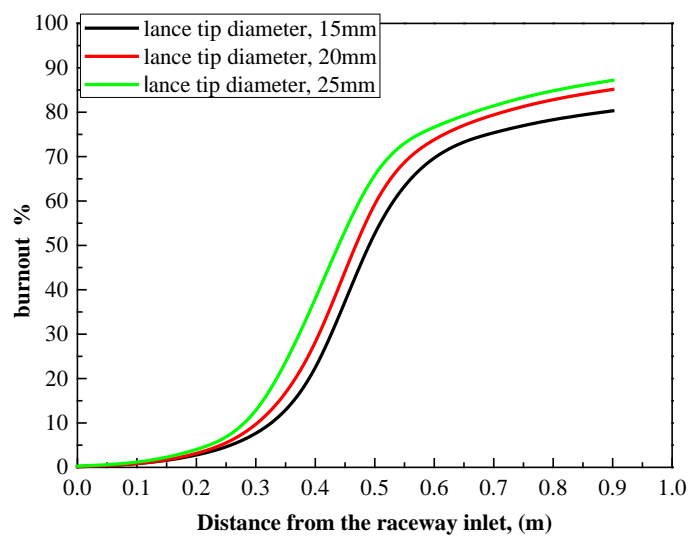

Fig. 5Effect of the lance tip area on the coal burnout changes in the raceway

To further study the behavior of coal combustion under different lance tip areas, the coal burnout at different positions of the raceway is calculated, as shown in Fig. 5. With increase of the lance tip area, the change trend of coal burnout has no significant difference. Before $0.2 \mathrm{~m}$ from the raceway inlet in the direction of axis $+X$, a slight increase of the coal burnout is observed. After $0.2 \mathrm{~m}$ in the direction of axis $+X$, the coal burnout rapidly increases until about $0.5 \mathrm{~m}$. Then the increasing trend of the coal burnout begins to slow down. With increase of the lance tip area, the coal burnout has no obvious differences before $0.2 \mathrm{~m}$ in the direction of axis $+X$. And at the distance of $0.2 \mathrm{~m}$, the obvious differences begin to appear. When the lance tip diameter is $15 \mathrm{~mm}$, the growth rate of the coal burnout slows down from the distance of $0.6 \mathrm{~m}$. However, when the lance tip diameter are $20 \mathrm{~mm}$ and $25 \mathrm{~mm}$, the growth rate of the coal burnout do not reduce much compare with that of the diameter $15 \mathrm{~mm}$. We can analyze this phenomenon from two aspects. Firstly, with increase of the lance tip area, the coal burnout is higher and more heat is produced. At the end of the raceway, the coal particles absorb more heat and release more volatile matter. On the other hand, the coal stream moves upward and the local oxygen around the coal particles is added, which is helpful for the coal combustion.

\section{Conclusions}

In this paper, a numerical model of the coal combustion simulated the lance-blowpipe-tuyere-raceway of the blast furnace was developed. The effect of coal lance tip position and area on coal combustion is investigated. The main conclusions are as follows:

(1) The coal burnout gradually increases with increase of the lance tip distance from the raceway. In the first part of the raceway, this way is very effective in improving the coal burnout. However, the effect is not very obvious in the second part of the raceway. This is mainly because, with increase of the lance tip distance, the oxygen is consumed in advance and the coal combustion is limited at the end of the raceway.

(2)The coal burnout gradually increases with increase of the lance tip area. On the one hand, the residence time of the coal particles increases with increase of the lance tip area. On the other hand, the coal streams move upward, where the oxygen concentration is higher.

\section{References}

[1] C. Ho, S. Wu, H. Zhu, A. Yu and S. Tsai, Experimental and numerical investigations of gouge formation related to blast furnace burden distribution, Miner. Eng. 22 (2009) 986-994.

[2] H. Suopajärvi, E. Pongrácz and T. Fabritius, Bioreducer use in Finnish blast furnace ironmaking-analysis of CO 2 emission reduction potential and mitigation cost, Appl. Energy 124 (2014) 82-93.

[3] F. M. Shen, B. Sundelin, K. Paulsson, E. Kapilashrami, G. Wei, M. S. Chu and Y. S. Shen, Industrial practice of BiPCI process of pulverized coal injection for blast furnace ironmaking at SSAB, Steel Res. Int. 79 (2008) 11. 
[4] M. S. Qin and B. Qi: Proc. IISC. The Sixth International Iron and Steel Congress., (1990), 589-595.

[5]Q. Min Shen and Z. Yu Ting, Blast furnace operation with full oxygen blast, Ironmak. Steelmak. 15 (1988) 287-92.

[6] A. T. Wijayanta, M. S. Alam, K. Nakaso, J. Fukai, K. Kunitomo and M. Shimizu, Combustibility of biochar injected into the raceway of a blast furnace, Fuel Process. Technol. 117 (2014) 53-59.

[7] A. T. Wijayanta, M. S. Alam, K. Nakaso, J. Fukai, K. Kunitomo and M. Shimizu, Numerical Study on Pulverized Biochar Injection in Blast Furnace, ISIJ Int. 54 (2014) 1521-1529.

[8] Y. S. Shen, D. Maldonado, B. Y. Guo, A. B. Yu, P. Austin and P. Zulli, Computational fluid dynamics study of pulverized coal combustion in blast furnace raceway, Ind. Eng. Chem. Res. 48 (2009) 10314-10323.

[9] Y. S. Shen, B. Y. Guo, A. B. Yu and P. Zulli, A three-dimensional numerical study of the combustion of coal blends in blast furnace, Fuel 88 (2009) 255-263.

[10]Y. S. Shen, A. B. Yu, P. R. Austin and P. Zulli, CFD study of in-furnace phenomena of pulverised coal injection in blast furnace: Effects of operating conditions, Powder Technol. 223 (2012) 27-38.

[11] Z. F. Zhou, Y. L. Liu, G. Wang, X. F. She, Q. G. Xue and J. S. Wang, Effect of Local Oxygen-enrichment Ways of Oxygen-coal Double Lance on Coal Combustion, ISIJ Int. 57 (2017) 279-285.

[12] Z. F. Zhou, H. L. Huo, G. Wang, Q. G. Xue, X. F. She and J. S. Wang, Effect of Oxygen - Coal Lance Configurations on Coal Combustion Behavior, Steel Res. Int. 88 (2017).

[13] S. W. Du, C. P. Yeh, W. H. Chen, C. H. Tsai and J. A. Lucas, Burning characteristics of pulverized coal within blast furnace raceway at various injection operations and ways of oxygen enrichment, Fuel 143 (2015) 98-106.

[14] C. P. Yeh, S. W. Du, C. H. Tsai and R. J. Yang, Numerical analysis of flow and combustion behavior in tuyere and raceway of blast furnace fueled with pulverized coal and recycled top gas, Energy 42 (2012) 233-240.

[15] Y. S. Shen, B. Y. Guo, A. B. Yu, P. R. Austin and P. Zulli, Three-dimensional modelling of in-furnace coal/coke combustion in a blast furnace, Fuel 90 (2011) 728-738. 